\title{
Logistics of Electronic Home-Project-Based Course
}

\author{
Samuel Kosolapov and Nissim Sabag
}

\begin{abstract}
Some educational approaches designed to replace traditional lecture-based courses are known: Active Learning, E-Learning, PBL and others. Educators in many famous universities agree that despite significant popularity of the above techniques, real-life laboratory is an obligatory requirement for the education of an electronic engineer. Although, several well-known electronic simulation-software can be successfully used as a valuable and nearly free educational tool, nevertheless students that never experienced real components may get the false impression that all cables are always good, all measurement devices are ideal and that electronic components always behave as described in the datasheet. Hence, traditional electronics laboratory with measurement equipment, electronic components and cables is still a must at least for the basic electronic courses in the first and second year of the curriculum. However, for some advanced electronic courses, an alternative organization course can be proposed: a home project-based course.

During the four semesters (2016-2018), groups of 20 students each ( 80 in total) were involved in two elective courses of that kind: Electronic Instrumentation and Real-Time DSP. In those courses, pairs of students were asked to execute small laboratory experiments at their homes by using electronic kits provided to them by the lecturer. Additionally, they implemented at home, and presented in the class two micro-projects using both simulation software and the above kits. At the end of each semester, $25 \%$ of the students $(20$ in total) were interviewed about their experience in the course. Only three were unsatisfied, while the other 17 students expressed very positive attitudes toward the course. A typical citation raised by some students is: "It's my first time doing something that really works, not just a simulation or an exercise." We believe the presented method increases both the interest and the understanding level of the students.
\end{abstract}

Index Terms-Active learning, electronic education, laboratory in electronic education, project-based-learning.

\section{INTRODUCTION}

Some educational approaches designed to replace traditional lecture-based courses are known: Active Learning [1], E-Learning [2], PBL and others. Educators in many famous universities agree that despite significant popularity of the above techniques, real-life laboratory is an obligatory requirement for the education of an electronic engineer [3]. Many educators emphasize the importance of simulations and computerized tools in engineering education. Thus, [4] suggests using simulation to assist statistical learning; [5] argues that there is benefit in using computer simulation in studying the basic fluid flow and heat transfer; [6] suggests using A LabVIEW-Based, Interactive Virtual Laboratory for Electronic Engineering Education and [7]

Manuscript received December 4, 2018; revised April 4, 2019.

Samuel Kosolapov and Nissim Sabag are with the Ort Braude College of Engineering, Isreal (e-mail: nsabag@braude.ac.il). reports on using Interactive Virtual Laboratory for Electronic Engineering Education. Nevertheless, the roots of learning by doing go back to Roger Beacon (1214-1294), who placed considerable emphasis on empiricism and has been presented as one of the earliest advocates of the modern scientific method [8]. Thus, important institutes like MIT [9] and others set in their curriculum of electrical engineering a substantial part of 'hands on' lab skills, using real electronics components and basic electronic equipment (such as scope, power supplies, signal generators, multi-meters, etc.).

In many cases, the elective and advanced courses require expensive equipment which are safely kept and installed in specially designed laboratory rooms. Therefore, a tendency towards remote laboratories and simulations became popular. Although several well-known electronic simulation-software can be successfully used as a valuable and nearly free educational tool, nevertheless, when using simulations only, students may never experience working with real components. In such a case, students may get the false impression that cables are always good, all measurement devices are ideal and that electronic components always behave as described in the data sheet. Hence, traditional electronics laboratory with real components and measurement equipment is obligatory. However, for some elective and advanced labs, an alternative organization is proposed: a "Home Project-Based Course".

According to this approach, the lecturer provides frontal lectures and exercises, but instead of in-campus laboratory, the lecturer equips the students with inexpensive sets, including Arduino and sensor/ actuator kit, in addition to Home Project-Based assignments. By using these kits, the students can work with real electronic components at home. The home assignments consist of Home Works and Home Micro-Projects. Each assignment must be well documented and sent to the lecturer by E-mail. For the Home micro-projects, a presentation should be submitted too.

The current paper describes the students' opinions about two courses: "Electronic Instrumentation" and "RT-DSP" in which the home project-based method was used.

\section{Methodology}

\section{A. Research Question}

What is the students' opinion toward learning the courses Electronic Instrumentation and Real-Time DSP through Home-Project-Based method?

\section{B. Research Tools}

The research tools used are in-depth interviews with students and a students' opinion questionnaire to collect information about students' satisfaction from the Home-Project-Based method. The questionnaire is a 
Likert-style containing questions about: The course difficulty level, course interest, the relevance of the Home-project-based assignments and the degree to which it assists students to understand the studied material. The questionnaire also contains questions about the lecture's quality.

\section{Research Population}

The research population consisted of more than 80 Electrical and Electronic Engineering students, who learned the courses Electronic Instrumentation and Real-Time DSP through Home-Project-Based method during four semesters in the years $2016-2018$. A sample of $25 \%$ of the students of each group (20 students in total) were interviewed about their thoughts concerning the Home-Project-Based method. Nevertheless, all the students were asked to fill an opinion questionnaire, 32 students completed it (about $40 \%$ ).

\section{Courses Description}

Two elective courses: Electronic Instrumentation and Real-Time DSP, are the core of the current paper. Each of the courses is one semester (14 weeks) long, during which the Home-Project-Based method was used. To perform home works (HW) and micro projects (MP), the students were equipped with inexpensive kits. The students were requested to perform three HWs and TWO MPs. Table I summarizes Hardware and Software included in the kits. An extremely simple (and inexpensive) Arduino UNO R3 Board, and 37 small sensors and actuators. The free Arduino IDE (software) was used to write "sketches" (programs) to enable getting signals from the sensors, process the signals and send output to the actuators. One simple example of an assignment is "Light control system", whereas a colored RGB-LED's light is set according to the mean of last 10 light level measurements (a photo resistor is used as a sensor). In case of low light level, relay module switch on additional lights, or in case of high light level, a buzzer starts making sounds.

The students (typically, two students executed one project) were required to implement the system with real components on a breadboard and an Arduino Board, write a program and confirm proper functioning of the designed project. In the end, the students were asked to document and present their work using power point, including photos showing the production and testing process of the project. The reporting procedure included emailing a report to the lecturer by using a special item name and a special attached file name.

An example of an Item name is: ABCD-EFGH-Z-YYYY-MM-DD, where ABCD are the last 4 digits of the first student's ID, EFGH are the last 4 digits of the second student's ID, and Z can be HW1, HW2, HW3 for homework or MP1, MP2 for micro-projects. YYYY-MM-DD is the reporting date in reverse order (it gives the lecturer an easy way to track the exact work and students). Two different Gmail accounts were dedicated for our two courses.

Different and more advanced hardware and software were used in the course RT-DSP, as shown in Table II. The development EasyPIC board was used to accept one or two signals, process them and presents the results on a color touch screen. The Arduino DUE board was used as a software-defined two-channel signal generator (the code of which students must write by using Arduino IDE). Students were expected to write the code by using DSP techniques studied during the lectures.

TABLE I: HARDWARE AND SOFTWARE SET FOR THE ELECTRONIC INSTRUMENTATION COURSE

\begin{tabular}{lll}
\hline \hline$\#$ & \multicolumn{1}{c}{ Hardware } & \multicolumn{1}{c}{ Software } \\
\hline 1 & Arduino UNO R3 Board & $\begin{array}{l}\text { Arduino IDE (free); Fritzing CAD } \\
\text { Software (free); Autodesk Tinkercad } \\
\text { Circuits. I/O (free) }\end{array}$ \\
2 & $\begin{array}{l}\text { Small Breadboard Matrix } \\
\text { Shield }\end{array}$ & - \\
3 & $\begin{array}{l}\text { Additional small-size } \\
\text { Breadboard }\end{array}$ & - \\
4 & $\begin{array}{l}\text { 37 Sensor Kit } \\
5\end{array}$ & $\begin{array}{l}\text { USB Cable and set of } \\
\text { coloured wires }\end{array}$ \\
\hline \hline
\end{tabular}

TABLE II: HARDWARE AND SOFTWARE SET FOR THE COURSE "RT-DSP"

\begin{tabular}{|c|c|c|}
\hline \# & Hardware & Software \\
\hline 1 & $\begin{array}{l}\text { EasyPic Fusion v7 board } \\
\text { with PIC } 32 \\
\text { PIC32MX795F512L MCU } \\
\text { installed }\end{array}$ & $\begin{array}{l}\text { PIC } 32 \text { MikroC Pro compiler (free up to } \\
16 \text { KB code size) } \\
\text { USB Dongle License for MikroC PIC } 32 \\
\text { Pro } 2017 \text { Tinkercad Circuits. I/O (free) }\end{array}$ \\
\hline 2 & Arduino DUE Board & Arduino IDE (free) \\
\hline 3 & $\begin{array}{l}\text { USB Cables and set of } \\
\text { coloured wires }\end{array}$ & - \\
\hline
\end{tabular}

\section{E. Course Organization}

The Home Project Based Courses demand time for the lecturer to explain Home Works and Micro-Projects, and to answer the students' questions. Additionally, time should also be dedicated to students' presentations of their Micro-Projects in class. All this requires some planning of the course organization. Both the lecturer and the students are very busy during this course in implementing home works and micro projects. Table III presents organization of the course "Electronic Instrumentation". The organization of the RT-DSP course is similar.

TABLE III: ORGANIZATION OF A HOME PROJECT BASED COURSE "ELECTRONIC INSTRUMENTATION"

\begin{tabular}{cc}
\hline \hline Lecturer & $\begin{array}{c}\text { Students } \\
\text { (Frontal Lectures and Exercises) }\end{array}$ \\
& (At home, before and after the \\
lecture)
\end{tabular}

1 Frontal Lecture: Goals and rules of Getting a first impression of the course. Live demonstration of the course, hardware and the Arduino UNO R3 board and 37 software to be used at home. Sensor kit to be used during the course

2 Detailed (step-by step) explanation how to install and configure Arduino IDE and how to create first "Blinking LED" applications by using the Arduino IDE

3 Frontal lecture: about complicated applications using timers and hardware interrupts.

Create a Blinking LED and Buzzer Arduino application by using Circuits.io simulator

Each pair of students gets a set of devices for home usage, from a lecturer

4 Frontal Lecture: About Sensors and Students are asked to create Actuators - properties, parameters 
and practical usage (including connection to the microcontroller)

Frontal Lecture: About the Sensors and Actuators of the 37-in-one Sensor Kit.

Explanation of Home Work \#1

6 Frontal Lecture: Explanation about the Set of Micro Projects \#

$7 \quad$ Frontal Lecture: Answering \#1 and Micro Projects \#1

8 Frontal Lecture: Theoretical material in accordance with the syllabus. Discussion concerning results of the First Home Work.

9 Lecturer serves as a chair of the students' project presentation and provide preliminary comments.

10 Frontal Lecture: Explanation about Home Work \#2 and Home Work \#3

11 Frontal Lecture: Explanation about

12 Frontal Lecture: Reserved time to answer students' question concerning home works and micro projects

13 Frontal Lecture: Reserved time to answer students' question concerning home works and micro project \#2

14 Lecturer serves as a chair of the Students' project presentation and provide preliminary comments. questions concerning Home Work the Set of Micro Projects \#2

(described during the

lectures)

Running examples using timers and interrupts. Start working on Home Work \#1

Random assign pairs of students to a particular Micro-Project \#1 to be executed

Emailing to the lecturer detailed report about Home Work \#1

Students have an option to resend report of the First

Home Work. To teach the students to write a

commensurate report

Before the lecture students, Emailed to the lecturer detailed report about their first Micro Project.

During the lecture pairs of students present their first Micro Projects in the class.

Working on the Home Works \#2 and \#3

Working of Home Works \#2 and \#3

Working of Home Works \#2 and \#3 and on Micro Project \#2

Working of Home Works \#2 and \#3 and on Micro Project \#2

Before the lecture students, Email the lecturer detailed report about Micro Project \#2. During the lecture time, pairs of students present First Micro Projects in the class.

\section{RESUlTS}

While writing the current paper, the course Electronic Instrumentation was provided three times, whereas course RT-DSP was provided once as "Home-Project-Based Course". The total number of students enrolled is 80 .

The students' opinion about the Home-Project-Based, as reflected in the courses Electronic Instrumentation and RT-DSP, are presented in Table IV. Table IV details the average opinion (in a scale of 5) of the students about: $\mathrm{A}$ - the course difficulty, B - course interest, C - the relevance of Home-project-based assignments and D - how much it helps to understand the studied material. The students' opinion about the lectures' quality is also presented.

The results show that the students' opinion about the courses, provided as "Home-Project-Based Course, is quite good (over 4 in a scale of 5) and their opinion about the lectures is even better.

Twenty five percent of the students (20 students out of 80) who studied the courses were interviewed about their opinion toward the Home-Project course method. Significantly, most of the interviewees (17 out of 20) expressed extremely positive sentiments about the Home-Project method. A typical citation from that group's words is: "This is my first time building something that is not a calculation or simulation, - something that I build with real components, and it really works."

TABLE IV: STUDENTS' OPINION ABOUT THE COURSES ELECTRONIC INSTRUMENTATION AND RT-DSP

\begin{tabular}{c|c|c|c|c|c|c|c}
\hline \hline $\begin{array}{c}\text { Number } \\
\text { of } \\
\text { Students }\end{array}$ & Year-Semester & A & B & C & D & Mean & $\begin{array}{c}\text { Lectures' } \\
\text { quality }\end{array}$ \\
\hline 11 & $2016-1$ & 4 & 4.3 & 3.9 & 4.3 & 4.1 & 4.4 \\
\hline 10 & $2016-2$ & 3.8 & 4.4 & 3.9 & 3.7 & 4.0 & 4.5 \\
\hline 6 & $2017-1$ & 3.5 & 4.5 & 4.2 & 4.3 & 4.1 & 4.3 \\
\hline 6 & $2018-1$ & 3.5 & 4.4 & 4.4 & 5.0 & 4.3 & 4.8 \\
& RT-DSP & & & & & & \\
\hline \hline
\end{tabular}

On the other hand, a minor number of students ( 3 out of 20) expressed a different opinion. They expected some challenging assignments. A typical citation from this group is: "well, I would expect more challenging projects with more elements." This small number of students prefer traditional laboratory-based courses as opposed to the Home-Project based method.

Additionally, it might be interesting to share with the lecturer the impressions of the level of the projects (each pair of students had a different project): most of the students (especially in the course RT-DSP) created a high-level real-time application with a commensurate GUI. However, a small number of students reveals some misunderstanding of the theoretical material learned.

\section{CONCLUSIONS}

The results of the current paper show that the Home-Project-Based Course approach can be useful for the electronic courses. This method enables the students to devote time at home, at their convenience, to perform meaningful learning through project work.

Abundance of inexpensive portable electronic kits make the use of Home-Project-Based method possible for courses like Electronic Instrumentation, RT-DSP, Image Processing and some others. However, the decision to use the described approach must take into account the specific course and the level of the students. For example, students that have had previous experience with practical building of the electronic systems found the lectures and exercises of the course "Electronic Instrumentation", home-work and micro projects interesting, but simple. In contrast, students with no such experience, found the same course more difficult and the execution of the home works and micro projects as "challenging, but time consuming".

\section{REFERENCES}

[1] T. Mandic and A. Baric, "Active-learning implementation proposal for course Electronics at undergraduate level," 40th International Convention on Information and Communication Technology, Electronics and Microelectronics (MIPRO), 2017. 
[2] U. Drofenik, J. W. Kolar, P. J. Duijsen, and P. Bauer, "New web-based interactive e-learning in power electronics and electrical machines," in Proc. Conference Record of the 2001 IEEE Industry Applications Conference. 36th IAS Annual Meeting (Cat. No.01CH37248), 2001.

[3] S. Nikolic, P. J. Vial, M. Ros, D. Stirling, and C. Ritz, "Improving the laboratory learning experience: A process to train and manage teaching assistants," IEEE Transactions on Education, vol. 58, no. 2, 2015.

[4] T. C. Liu, Y. C. Lin, Kinshuk, and M. Chang, "Individual differences in learning with simulation tool: A pilot study," in Proc. 8th IEEE International Conference on Advanced Learning Technologies, pp. 501-503, 2008.

[5] W. M. Clark, "Computer simulations to correct misconceptions in fluid flow and heat transfer fundamentals," in Proc. IEEE Frontiers in Education Conference, October 2010.

[6] Z. Yi, J. Jian-Jun, and F. Shao-Chun, "A LabVIEW-based, interactive virtual laboratory for electronic engineering education," International Journal of engineering Education, vol. 21, no. 1, pp. 94-102, 2005

[7] M. T. Valdez, C. M. Ferreira, M. J. M. Martins, and F. P. M. Barbosa, "Virtual labs in electrical engineering education - The VEMA environment," Information Technology Based Higher Education and Training (ITHET), 2014.

[8] Roger Beacon. [Online]. Available: http://he.wikipedia.org/wiki/Roger Beacon

[9] ocw.mit.edu. [Online]. Available: https://ocw.mit.edu/courses/electrical-engineering-and-computer-scie nce/6-091-hands-on-introduction-to-electrical-engineering-lab-skills-j anuary-iap-2008/

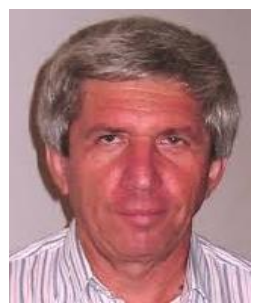

Samuel Kosolapov holds an M.Sc in physics from the Moscow Institute of Physics and Technology, MFTI, Moscow, USSR (1976) and a PhD in biophysics from Research Institute for Biological Testing of Chemical Compounds, Moscow, USSR (1982). He is a senior lecturer in the Department of Electronics \& Electrical Engineering, ORT Braude College, Karmiel, Israel. He was Head of Student' Excellence Program, member of the Collegial Committee of Academic Affairs, and many other academic positions at the ORT Braude College. He also received 3 prizes for being an outstanding faculty member. He has published 22 refereed papers in international journals, 3 chapters in refereed paper books and 38 papers in refereed conference proceedings.

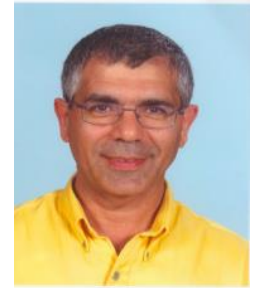

Nissim Sabag holds a BSc in EEE (1982), a BSc, MSc, $\mathrm{PhD}$ (1995, 1998 and 2002 respectively), in Technology and Science Education from the Technion-Israel Institute of Technology. He is a senior lecturer and deputy head of the Department of Electronics \& Electrical Engineering, ORT Braude College, Karmiel, Israel. He was: Head of academic administration, Chair of the Collegial Committee of Academic Affairs, Member of the higher academic council and many other academic positions at the ORT Braude College. He was the head of a project involving eight high schools for improving learning and teaching of electronics for this he received a Certificate of recognition for enhancing the teaching level of electronics from the Ministry of Education. He also received 14 prizes for being an outstanding faculty member. He has published 15 refereed papers in international journals, 2 chapters in refereed paper books and 18 papers in refereed conference proceedings. 